\title{
Stillbirths in Germany: On the rise, but no additional increases during the first COVID-19 lockdown
}

\author{
Maxi Stella Kniffka, B.A ${ }^{1}$; Natalie Nitsche, PhD $^{1}$; Roland Rau, Prof. ${ }^{1,2}$; Mine Kühn, PhD $^{1}$ \\ ${ }^{1}$ Max Planck Institute for Demographic Research, Konrad-Zuse-Straße 1, 18057 Rostock, Germany \\ ${ }^{2}$ University of Rostock, Dept. Of Sociology and Demography, Chair of Demography, Ulmenstraße 69, 18057 \\ Rostock, Germany \\ Correspondence to: Maxi Stella Kniffka, B.A, Max Planck Institute for Demographic Research, Konrad-Zuse- \\ Straße 1, 18057 Rostock, Germany, kniffka@demogr.mpg.de
}

\begin{abstract}
Background

A growing body of studies on the indirect effect of the COVID-19 pandemic on stillbirths shows mixed and contextdependent evidence, even within high-income countries. We examined possible changes in the stillbirth rate in Germany during the first COVID-19 lockdown.
\end{abstract}

\section{Methods}

We used population-level data on live and stillbirths occurring between January 1995 and July 2020 and applied negative binomial regression to estimate the yearly and monthly stillbirth rate in this period. We compared the actual stillbirth rate to the expected figure for the first seven months of 2020, based on prediction intervals derived from the detected time trend.

\section{Findings}

We detected a steady increase in stillbirths in Germany since 2013, which was preceded by a declining (1995-2004), and then plateauing (2005-2012) stillbirth rate. The stillbirth rate for January 2020 through July 2020 (4-148) was slightly lower than the stillbirth rate in the same period in 2019 (4.242). Furthermore, all monthly stillbirth rates during the first half of 2020 lie inside the $95 \%$ prediction interval of expected stillbirth rates for this period. Thus, stillbirths in Germany have neither increased nor decreased during the country's first COVID-19 lockdown period.

\section{Interpretation}

In contrast to other European countries, stillbirth rates have been on the rise in Germany in the last decade. However, stillbirth rates during the first seven months of 2020 were not higher than expected. Our results suggest that stillbirth rates have neither increased nor decreased during the first-wave COVID-19 lockdown in this highincome setting. Further studies on the causes of the increasing stillbirth trend in Germany are needed, however.

\section{Funding statement}

No external funding was received for this research. 


\section{Research in context}

\section{Evidence before this study}

Before conducting this study, we searched Google Scholar for studies published since January 1, 2020 with the search terms: "stillbirth COVID-19", "pregnancy output COVID-19", and "fetal death COVID-19". We selected all studies that observed the indirect effect of the pandemic on stillbirths in full hospital, regional, and country populations. We found one meta-study and ten single-country studies, all of which focused on the first COVID-19 wave. Studies documented mixed evidence due to diverse contexts, data selections, and methodologies. For highincome countries, three register-data based studies showed no pandemic-related increases in the stillbirth rates, while six hospital-based studies documented increases in stillbirths, and one did not. Most studies compared stillbirth rates during the first wave of the pandemic with short-term pre-pandemic rates without assessing indirect pandemic effects in the light of longer-term trends. No previous study documented the indirect effect of the COVID-19 pandemic on stillbirth rates in Germany and, furthermore, no study has documented trends in stillbirth rates for Germany since 2012.

\section{Added value of this study}

Our study is the first to provide evidence of the indirect effect of COVID-19 on stillbirths in Germany and to assess stillbirth rates during the first wave of the pandemic in the context of longer-term trends. Furthermore, we documented trends in the stillbirth rate in Germany since 1995, uncovering a previously unknown upward trend since 2013.

\section{Implications of all the available evidence}

Population-level increases in stillbirths may be of no immediate concern in European high-income countries during times of lockdowns with low infectious COVID-19 activity, even though shifts in certain hospitals or regions may have occurred as suggested by other studies. The indirect effect of the COVID-19 pandemic on stillbirth rates thus appears to be context dependent. This suggests that SARS-CoV-2 virus activity, pandemic control measures, health care systems, population health, or other factors are important moderators of COVID-19 lockdowns on perinatal outcomes. Moreover, perinatal health outcomes observed during the pandemic need to be assessed in the context of previous trends related to these outcomes and evaluated in light of the expected numbers of the perinatal event of interest during the pandemic, based on previous trends. Finally, further research is needed to investigate the causes of the detected rise in the German stillbirth rate that occurred over the last decade.

\section{Introduction}

As in many other countries affected by the COVID-19 pandemic, the German federal and state governments responded to increasing numbers of COVID-19 cases and deaths by taking drastic public health measures intended to slow down the transmission rate of the SARS-CoV-2 virus. During the pandemic's first wave, large parts of public life were shut down from March 22, 2020 for the following three months. To keep intensive care beds available, the German government ordered hospitals to postpone non-emergency procedures and surgeries. First comparisons of hospitalizations during the pandemic (March 16, 2020 to April 5, 2020) and pre-pandemic (corresponding dates in 2019) periods, based on data from one of the largest insurance companies in Germany, indicate a decrease of $16 \%$ in pregnancies, births, or postpartum-related hospitalizations and a decrease of $14 \%$ in hospitalizations related to diseases of the fetus or the newborn. ${ }^{1}$

Scholars expressed concerns since the pandemic's early stages that the COVID-19 measures might disrupt the delivery of health services, including reproductive and maternal health care services, and it would reduce care-seeking behavior. The scientific community consequently called for studies on the indirect effect of COVID-19 on perinatal and maternal outcomes in general and on stillbirths in particular. ${ }^{2}$

A year later, evidence from the growing body of studies investigating the possible correlation between COVID-19 lockdown measures and stillbirths, reflects mixed results. A recently published meta-analysis indicates that stillbirth rates have increased during the pandemic, in particular in low- and middle-income countries, but not in high-income settings. ${ }^{3}$ Indeed, several hospital-based studies from low-, middle- but also high-income countries have reported a 
rise in stillbirths during the pandemic. There is evidence, based on nine hospitals in Nepal and four hospitals in western India, that the risk of stillbirths has significantly increased during the lockdown in the spring of 2020 compared to the weeks before the lockdown. ${ }^{4,5}$ Similarly, a study comparing the incidence of stillbirths based on data from one hospital in London during the pandemic (February 2020 to June 2020) to the pre-pandemic period (October 2019 to January 2020), found an increase in stillbirth incidence from 2.38 per 1000 births to 9.31 per 1000 births; none of which were associated with known COVID-19 infections. ${ }^{6}$ Higher stillbirth rates during the pandemic were also reported in studies that made allowances for seasonal variations in live births and stillbirths. A study based on one hospital in Israel indicates a significant increase in stillbirth rates in the beginning of the pandemic (February 21, 2020 to April 30, 2020) compared to the corresponding periods from 2017 to 2019.7 Another study, based on a hospital discharge database from the Lazio region in Italy, reported an increase in stillbirth rates when comparing the period March 2020 to May 2020 with the corresponding period in $2019 .{ }^{8}$

In contrast, no evidence for an increase in stillbirths was found in a study based on data from two Philadelphia (USA) hospitals that compared stillbirth rates for the period March 2020 to June 2020 with the same months in 2018 and 2019 (pre-pandemic). ${ }^{9}$ This finding is in line with the four available studies on stillbirths in high-income countries based on population-level data. There was no evidence of increases in stillbirths in England, regionally or nationally, in the period April 2020 to June 2020 compared to the same months in $2019,{ }^{10}$ or when a longer pre-pandemic period of up to five years was taken into account in studies on the Castilla-y-León region in Spain, ${ }^{11}$ Sweden, ${ }^{12}$ and Austria. ${ }^{13}$

These mixed results on stillbirths in high-income countries may be caused by selectivity issues in the studies using hospital data; findings from the representative population-level studies likely are more robust. Nonetheless, most previous studies that explored the indirect effect of the COVID-19 pandemic on stillbirths focused on comparing stillbirth rates during the pandemic to relatively short pre-pandemic periods, ranging from one to five years prior to the pandemic. To account for random fluctuations in the number of stillbirth events and for pre-pandemic trends in stillbirth rates, particularly in high-income countries where stillbirths are rare events, it is, however, of great importance to consider longer-term trends related to stillbirths when assessing potential changes in stillbirth rates during the pandemic. Stillbirth rates in most high-income countries have continually declined in the last few decades, despite differences in overall stillbirth burdens and the magnitude of decline. ${ }^{14,15}$ This means that assessments of pandemic-related changes in stillbirths in 2020 would ideally be based on comparing the observed numbers of stillbirths during a specific 2020 pandemic time window with the expected number of stillbirths for the same period, predicted by taking longer stillbirth time trends into account. Therefore, our study aims at assessing the indirect effect of the COVID-19 pandemic on stillbirths in Germany by comparing the observed stillbirth rate in March 2020 to June 2020 with the expected stillbirth rate considering long-term trends in stillbirths since 1995, using full population data from statistical offices.

\section{Methods}

\section{Population-based data}

The data for pre-pandemic stillbirth rates in Germany was gathered from the Federal Statistical Office. ${ }^{16,17}$ They provided the total number of live and stillbirth events in Germany on a monthly basis from 1990 up to 2019, as well as the monthly number of live births for each federal state. The monthly provisional number of births for the whole of Germany and for each federal state from January 2020 to July 2020 was also provided by the Federal Statistical Office. Since the official statistics for stillbirths are not compiled until the summer of the following year, the provisional figures for stillbirths had to be obtained from the statistical offices of the respective federal states. ${ }^{18-32}$ With the exception of Thuringia, the number of stillbirths from January until July 2020 were provided by the statistical offices of each federal state. All numbers for 2020 are preliminary figures. Since the statistical office of Thuringia did not provide stillbirth data for 2020, we collected data on the monthly number of stillbirths from 1995 until 2019 for Thuringia to enable us to exclude Thuringia's live births and stillbirths from our analysis. ${ }^{33-50}$

\section{Associated analyses}

We deducted the monthly live and stillbirths for Thuringia from the data for Germany as a whole to analyze the trends in stillbirths for Germany. Thuringia was excluded due to data availability constraints. 
We then compared the observed monthly number of stillbirths per 1000 births in January 2020 through July 2020 with a) the observed number of stillbirths and b) the predicted number of stillbirths for the same time period. The prediction is based on the stillbirth trend detected in the data from January 1995 through December 2019. The prediction rests on a Generalized Additive Model (GAM), ${ }^{51,52}$ where we assume that the number of stillbirths follows a negative binomial distribution. ${ }^{53,54}$ The total number of births, i.e. stillbirths and live births combined, serves as a (log) offset. This offset does not only take care of changes in the underlying population structure, but also eliminates the effect of different lengths of months. The GAM contains two smooth components: one for the secular stillbirth trend observed over time, and one for the seasonal component, to adjust for seasonality in both the occurrence of births and stillbirths. Both smooth components are estimated using P-splines, ${ }^{55}$ which are widely used to estimate, smooth, and analyze mortality ${ }^{56,57}$ The definition of what counts as a stillbirth has changed twice in Germany during the observation period. ${ }^{17}$ Therefore, an indicator variable measures whether the old definition (January 1995 to October 2018) or the new definition (November 2018 to date) of stillbirths was in use. Prediction intervals were derived analytically using the quantile function of the negative binomial distribution with the seven estimates for the mean $\left(\mu_{1}, \mu_{2}, \mu_{3}, \ldots, \mu_{7}\right)$ from the GAM for January, February, March, ..., July 2020 and the estimate for parameter $\theta$, which controls the level of overdispersion.

\section{Results}

Table 1 shows a descriptive comparison between the observed stillbirth rate for the periods January to July 2019 and 2020 respectively. A slight decrease in the observed stillbirth rate is indicated in the time window of January 2019 to July 2019 (4.242) when compared with the same time window in 2020 (4.148). We compared the descriptive stillbirth rate for 2020 with the 2019 rate only because we could not control the effect of the definition change in 2018 in our descriptive results.

Figure 1 displays stillbirth rates in Germany from January 1995 until July 2020. Panel A shows annual observed and estimated stillbirth rates, with $95 \%$ confidence intervals around the estimated means. The stillbirth rate in Germany has continuously decreased between 1995 and 2006, but then plateaued until 2012. However, a reversal of this trend occurred in 2013; an ongoing and statistically significant increase in the stillbirth rate has occurred since. Between 2012 and 2018, the stillbirth rate in Germany has increased by 7.608 percent. Panels B and C display the monthly stillbirth rate from January 1995 until July 2020. The estimates in panel C reflect the control for seasonality in live birth and stillbirth rates, whereas the estimates in panel B do not. Monthly stillbirth rates in January 2020 to July 2020 lie in the $95 \%$ prediction interval for both types of predictions. Hence, the rate of stillbirths in Germany in the first half of 2020 has been neither higher nor lower than the expected rate without the pandemic's impact. Note that predicted stillbirth rates for 2020 are slightly higher than estimates in previous years, given the increasing trend over time in German stillbirths. The seasonal pattern of observed stillbirths for 2020 shows similarities with the pattern observed in 2019, with high peaks in May and March and a lower stillbirth rate in the other months. 


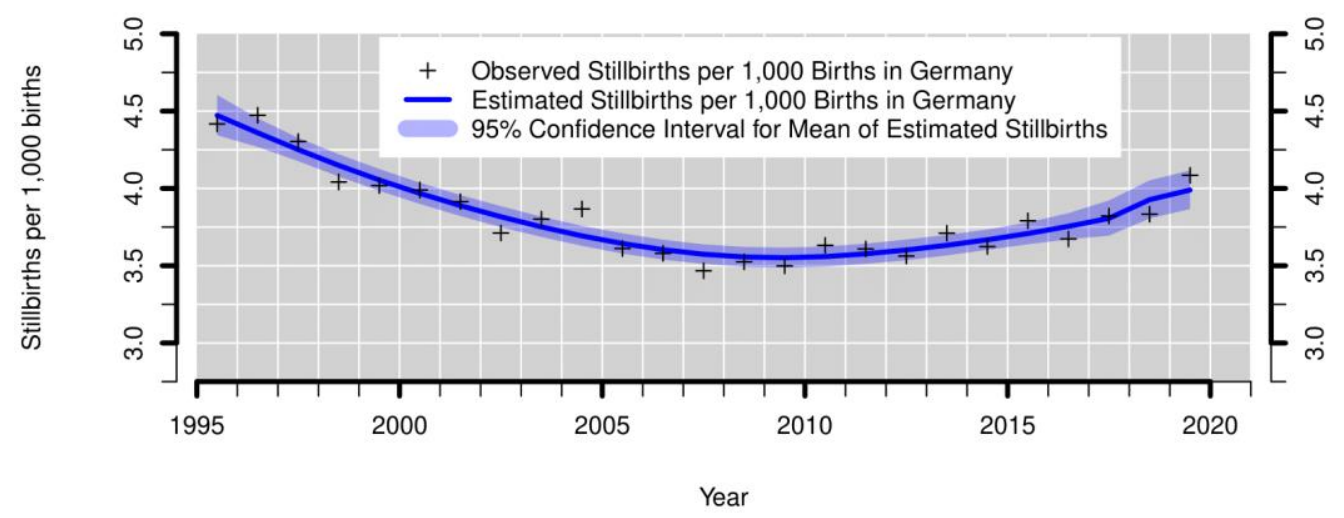

Observed and Estimated Monthly Stillbirths per 1,000 Births in Germany 1995-2019 Observed and Predicted Monthly Still Births per 1,000 Births in Germany Jan-Jul 2020

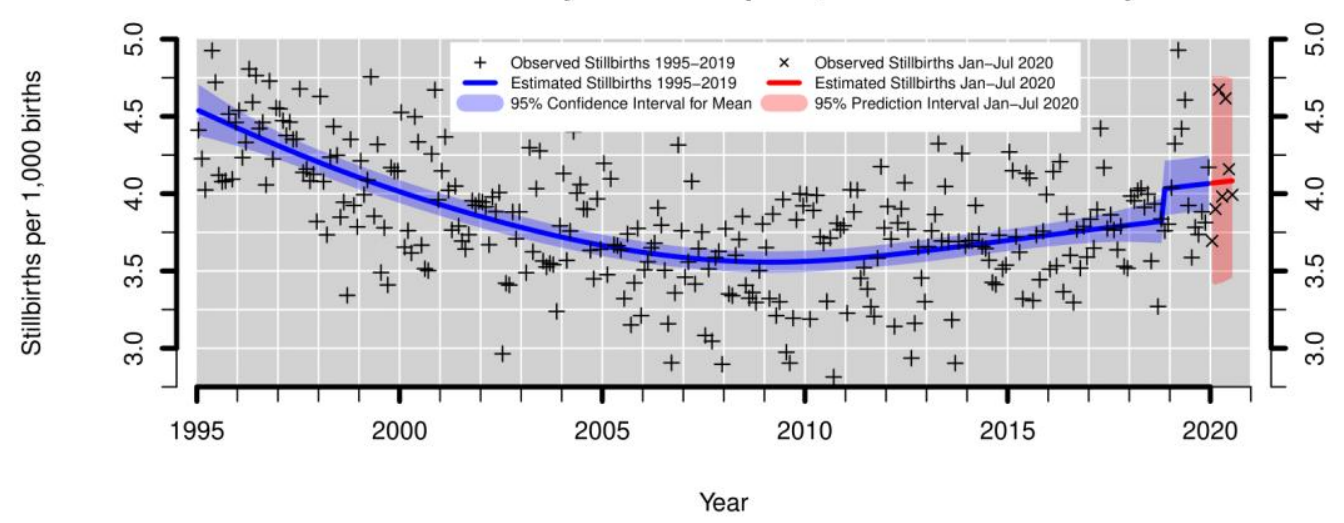

C Observed and Estimated Monthly Stillbirths per 1,000 Births in Germany 1995-2019 Observed and Predicted Monthly Still Births per 1,000 Births in Germany Jan-Jul 2020 (incl. Seasonality)

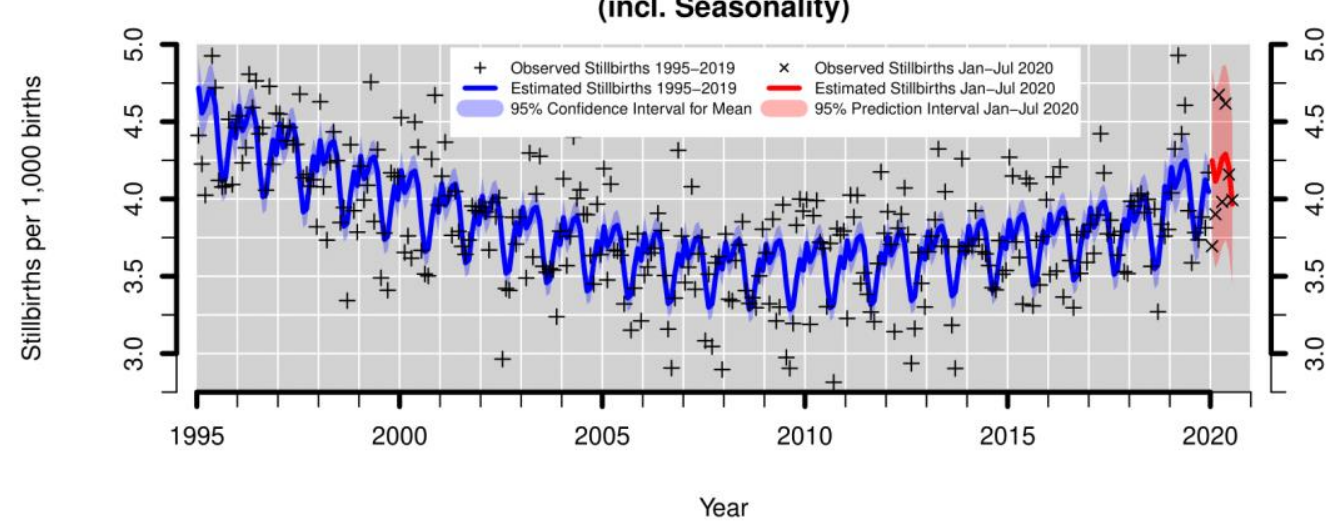

Figure 1: Panel A: Annually observed and estimated stillbirth rates for Germany except Thuringia, from 1995 until 2019, estimated by a negative binomial model in a Generalized Additive Model framework controlling for definition change. Panel B: Monthly observed, estimated and predicted stillbirth rates for Germany except Thuringia, from 1995 until 2020, estimated and predicted by a negative binomial model in a Generalized Additive Model framework controlling for definition change. Panel C: Monthly observed, estimated and predicted stillbirth rates for Germany except Thuringia, from 1995 until 2020, estimated and predicted by a negative binomial model in a Generalized Additive Model framework controlling for definition change and seasonality ${ }^{16-50}$ 
Table 1 displays monthly predicted stillbirth rates for 2020 in Germany, excluding Thuringia. Supplementary Tables 2 and 3 display the annual and monthly stillbirth estimations until 2019.

\begin{tabular}{|c|c|c|c|}
\hline Year & Month & Observed Stillbirth rate & Predicted Stillbirth rate $(95 \% \mathrm{CI})$ \\
\hline 2020 & Jan & $3 \cdot 694$ & 4.2483 .6774 .846 \\
\hline 2020 & $\mathrm{Feb}$ & $3 \cdot 901$ & $4.1133 .5514 \cdot 706$ \\
\hline 2020 & Mar & $4 \cdot 674$ & $4 \cdot 1703.6074 .758$ \\
\hline 2020 & Apr & $3 \cdot 981$ & 4.2653 .6944 .858 \\
\hline 2020 & May & $4 \cdot 617$ & 4.293 .7354 .869 \\
\hline 2020 & Jun & $4 \cdot 158$ & 4.2073 .6584 .781 \\
\hline 2020 & Jul & $3 \cdot 993$ & 3.9663 .4434 .499 \\
\hline 2019 & Average Jan to Jul & $4 \cdot 242$ & $\cdots$ \\
\hline 2020 & Average Jan to Jul & $4 \cdot 148$ & 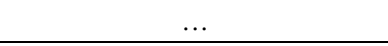 \\
\hline
\end{tabular}

\section{Discussion}

This study examines stillbirth rates in Germany before and during the first wave of the COVID-19 pandemic. To assess whether the pandemic has indirectly affected the occurrence of stillbirths, we compared observed stillbirth rates in January 2020 to July 2020 with a) observed stillbirth rates in 2019 and b) estimated stillbirth rates for the first half of 2020, which we derived from modeling stillbirth trends since 1995. Our analyses used full population data (except for the state of Thuringia) obtained from German statistical offices. We found that stillbirth rates have neither increased nor decreased during the first wave of the COVID-19 pandemic and associated lockdown in Germany. The observed stillbirth rate in January 2020 to July 2020 was slightly lower than in the corresponding period in 2019. However, all monthly stillbirth rates observed in the first half of 2020 lie within the $95 \%$ confidence interval of expected stillbirth rates for this period.

Our results corroborate findings from the few other available studies on high-income countries based on populationlevel data, which have detected no increase in stillbirths during the first wave of the COVID-19 pandemic. . $^{9-13}$ Furthermore, our findings show the importance of accounting for underlying trends in stillbirth rates when assessing potential pandemic-related changes. We detected an increasing and previously undocumented population-level trend in the stillbirth rate in Germany since 2013. In our analyses, findings on stability in stillbirth rates during the first pandemic wave are robust, regardless of whether we compare average rates from 2020 to those in 2019, or whether we compare monthly observed stillbirth rates with expected monthly rates based on estimates using long-term trends in stillbirth rates. However, declining (or increasing) trends in stillbirth rates that may have been present prepandemic in other countries or regions should nonetheless be factored in when assessing indirect pandemic effects on stillbirth rates and other perinatal outcomes. An increase in late fetal death rates from 2008 to 2012 in Germany was also reported by Schwarz et al., ${ }^{58}$ based on routine perinatal hospital data covering $98 \cdot 5$ percent of births in Germany. They found a correlation between an overall increase in maternal age and neonatal morbidity. ${ }^{58}$ Further research on the causes of the ongoing increasing stillbirth trend in Germany is needed. It should, for instance, examine whether the increase in stillbirth rates after 2012 is also related to increases in maternal age, and whether it may be caused by increasing proportions of pregnancies conceived with the help of assisted reproduction technology, which appears to have a slightly elevated risk of stillbirths. ${ }^{59}$

The major strength of our study lies in the full-coverage population-level data. The data reflects the total population of Germany instead of selected hospitals only. It is therefore representative of perinatal outcomes in the whole country. Furthermore, the extensive data coverage of monthly rates from 1995 to 2020 enabled us to analyze indirect pandemic effects on stillbirths in the context of the long-term trend in Germany, which revealed a previously undocumented ongoing and significant increase in the country's stillbirth rate since 2013. Our monthly estimates further enabled us to correct for seasonality in expected live and stillbirth rates. 
Despite its strengths, our study has limitations. The aggregated level data does not provide information that allows for analyses of the distribution or causes of the stillbirths. Hence, no detailed information on the mothers or pregnancies, such as age of the women, the gestation week, or maternal illnesses is available. This information is important to analyze group-specific pandemic impacts. Further, we can only measure the indirect effect of the pandemic and the lockdown because no information on the incidence of COVID-19 cases is available in our sample. Women with COVID-19 infection may carry a double burden; studies show that they run an increased risk of stillbirth, which could be due to either the direct effect of an infection or the indirect effect of the pandemic. ${ }^{60}$ Further, the data is provisional, and may not be $100 \%$ accurate. The preliminary data for the live and stillbirths in 2020 reflects the month of report and not by month of event. Thus, the monthly distribution of stillbirths in the final data, which will be published in the summer of 2021, may vary slightly from the provisional data we are currently using. However, it is unlikely that the total number of stillbirths in the first half of 2020 will change, and our results should therefore not be affected. ${ }^{21}$ Another limitation is the restricted comparability between the years before and after Germany's change of the definition of stillbirth in November 2018. Even though we made allowances for the definition change, it should be mentioned that it is best to compare the data from 2020 with the data from 2019.

We documented no changes in stillbirth rates during the first wave of the COVID-19 pandemic in Germany, but it should be noted that our study period only covers until the end of July 2020. In Germany, the total documented caseload of COVID-19 infections rates during the first wave was low, while the number of infections during the second and subsequent waves (which started after our observation window period) were higher, and the health care system was more affected. ${ }^{61}$ It will remain important to analyze potential changes in the rate of stillbirths when more data will become available in the summer of 2021.

Finally, our findings are context dependent. Germany has a high-quality health care system that provides extensive medical services to almost all pregnant women. ${ }^{62}$ Furthermore, the German Board and College of Gynecology and Obstetrics appealed in April 2020 to pregnant woman to go to hospital when needed and to not decline necessary clinic visits, which could result in poor pregnancy outcomes like stillbirths. Expecting parents were urged not to risk the health of mothers and unborn children due to fear of infection at the hospital. ${ }^{63}$ These factors may have contributed to the stability of stillbirth rates during the first wave of the pandemic in Germany.

\section{Data sharing}

Annual and monthly observed and estimated stillbirth rates on country level in Germany, except for the state of Thuringia, can be found in Tables 3 and 4 in the appendix. Complete annual and monthly live birth counts are available from the German Federal Statistical Office. Stillbirth counts were provided by states' statistical offices through data requests; they need to remain confidential and cannot be shared.

\section{Authors' contributions}

MSK, NN, and MK conceptualized the study. MSK collected and prepared the data. MSK, NN and MK verified the data. RR did the data analysis and visualized the results. MSK wrote the first draft of the manuscript. All authors contributed to the subsequent drafts and to the final manuscript. All authors had full access to all the data in the study and all the authors had the final responsibility for the decision to submit it for publication.

\section{Conflict of interest}

We declare that we have no conflicts of interests.

\section{Funding statement}

No external funding was received for this research.

\section{Acknowledgement}

We thank all the employees of the Federal Statistical Office (Destatis) and the statistical offices of the respective federal states for providing the regional live- and stillbirths data and the interest in our project. We further thank Mikko Myrskylä for helpful comments on an earlier version of this manuscript. 


\section{References}

1 Günster C, Drogan D, Hentschker C, et al. WIdO-Report: Entwicklung der Krankenhausfallzahlen während des Coronavirus-Lockdowns. Nach ICD-Diagnosekapiteln und ausgewählten Behandlungsanlässen. Berlin 2020.

2 Homer C S, Leisher S H, Aggarwal N, et al. Counting stillbirths and COVID 19 - there has never been a more urgent time. The Lancet Global Health 2020, 9(1), e10-e11. Available from: https://doi.org/10.1016/ S2214109X(20)30456-3

3 Chmielewska B, Barratt I, Townsend R, et al. Effects of the COVID-19 pandemic on maternal and perinatal outcomes: a systematic review and meta-analysis. The Lancet Global Health 2021. Available from: https://doi.org/10.1016/S2214-109X(21)00079-6

4 KC A, Gurung R, Kinney MV, Sunny AK, et al. Effect of the COVID-19 pandemic response on intrapartum care, stillbirth, and neonatal mortality outcomes in Nepal: a prospective observational study. In: Lancet Global Health 2020, 8, (e1273-81). Available from: https://doi.org/10.1016/S2214-109X(20)30345-4

$5 \quad$ Kumari V, Mehta K, Choudhary R: COVID-19 outbreak and decreased hospitalization of pregnant women in labour. In: The Lancet Global Health 2020, 8.9 (e1116-17). Available from: https://doi.org/10.1016/S2214109X(20)30319-3

6 Khalil A, von Dadelszen T, Ugwumadu A, O`Brien P, Magee L: Change in the Incidence of Stillbirth and Preterm Delivery During the COVID-19 Pandemic. American Medical Association 2020 (324, 7).

7 Mor M, Kugler N, Jauniaux E, et al. Impact of the COVID-19 Pandemic on Excess Perinatal Mortality and Morbidity in Israel. Am J Perinatol 2021, 38(04), 398-403.

8 De Curtis M, Villani L, Polo A. Increase od stillbirth and decrease of late preterm infants during the COVID-19 pandemic lockdown. Atch Dis Child Fetal Neonatal Ed 2020. Available from: doi:10.1136/fetalneonatal2020-320682

$9 \quad$ Handley S C, Mullin A M, Elovitz M A, et al. Changes in preterm birth phenotypes and stillbirth at 2 Philadelphia hospitals during the SARS-CoV-2 pandemic, March-June 2020. JAMA 2021, 325(1), 87-89. Available from: https://doi:10.1001/jama.2020.20991

10 Stowe J, Smith H, Thurland K, Ramsay M E, Andrews N, Ladhani S N. Stillbirths during the COVID-19 pandemic in England, April-June 2020. JAMA 2021, 325(1), 86-87. Available from:

https://doi:10.1001/jama.2020.21369

11 Arnaez J, Ochoa-Sangrador C, Caserío S, et al. Lack of changes in preterm delivery and stillbirths during COVID-19 lockdown in a European region. Eur J Pediatr 2021, 1-6. Available from:

https://doi.org/10.1007/s00431-021-03984-6

12 Pasternak B, Neovius M, Söderling J, et al. Preterm Birth and Stillbirth During the COVID-19 Pandemic in Sweden: A Nationwide Cohort Study. Ann Intern Med 2021. Available from: https://doi.org/10.7326/M206367

13 Farr A, Falcone V, Wagner M. Commentary to Pasternak et al. 2021. Ann Intern Med 2021, Vienna.

14 Blencowe H, Cousens S, Jassir F B, et al. National, regional, and worldwide estimates of stillbirth rates in 2015, with trends from 2000: a systematic analysis. The Lancet Global Health 2016, 4(2), e98-e108.

15 Smith L K, Hindori-Mohangoo A D, Delnord M, et al. Quantifying the burden of stillbirths before 28 weeks of completed gestational age in high-income countries: a population-based study of 19 European countries. The Lancet 2018, 392(10158), 1639-1646. 
16 Statistisches Bundesamt (Destatis). Lebendgeborene: Bundesländer, Monate, Geschlecht. Wiesbaden: Statistisches Bundesamt (Destatis) 2020 [cited 2.11.2020]. Available from: https://wwwgenesis.destatis.de/genesis//online?operation=statistic\&code=12612\&levelindex $=1 \&$ levelid=1610367596593\#abrea dcrumb

17 Statistisches Bundesamt (Destatis). Totgeborene insgesamt. Deutschland. Wiesbaden: Statistisches Bundesamt (Destatis) 2020 [cited 21.10.2020] [Data request]

18 Amt für Statistik Berlin-Brandenburg. Totgeborene insgesamt in Berlin und im Land Brandenburg 2020 nach Monaten. Potsdam: Amt für Statistik Berlin-Brandenburg 2020 [cited 22.10.2010] [Data request]

19 Bayrischen Landesamt für Statistik. Totgeborene nach Monaten 2020. Führt:Bayrisches Landesamt für Statistik 2020 [cited 12.01.2021] [Data request]

20 Hessisches Statistisches Landesamt. Datenanfrage Totgeburten 2020. Wiesbaden: Hessisches Statistisches Landesamt 2020 [cited 29.10.2020] [Data request]

21 Landesamt für Statistik Niedersachsen. Totgeborene in Niedersachsen. Hannover: Landesamt für Statistik Niedersachsen 2020 [cited 16.11.2020] [Data request]

22 Landesbetrieb Information und Technik Nordrhein-Westphalen. Totgeborene - kreisfreie Städte und Kreise - Monat (ab 2000). Düsseldorf: Landesbetrieb Information und Technik Nordrhein-Westphalen 2020 [cited 11.1.2021] Available from: https://www.landesdatenbank.nrw.de/ldbnrw/online\#astructure

23 Statistisches Amt Mecklenburg-Vorpommern. Natürliche Bevölkrungsbewegung in Mecklenburg Vorpommern. 1. Vierteljahr 2020. Schwerin: Statistisches Amt Mecklenburg-Vorpommern 2020 [cited 20.10.2020] Available from: https://www.laiv-mv.de/Statistik/Zahlen-und-Fakten/Gesellschaft-\&-Staat/Bevölkerung

24 Statistisches Amt Mecklenburg-Vorpommern. Natürliche Bevölkrungsbewegung in Mecklenburg Vorpommern. 2. Vierteljahr 2020. Schwerin: Statistisches Amt Mecklenburg-Vorpommern 2020 [cited 20.10.2020] https://www.laiv-mv.de/Statistik/Zahlen-und-Fakten/Gesellschaft-\&-Staat/Bevölkerung

25 Statistisches Amt Mecklenburg-Vorpommern. Natürliche Bevölkrungsbewegung in Mecklenburg Vorpommern. 3. Vierteljahr 2020. Schwerin: Statistisches Amt Mecklenburg-Vorpommern 2020 https://www.laiv-mv.de/Statistik/Zahlen-und-Fakten/Gesellschaft-\&-Staat/Bevölkerung [Accessed on 27.12.2020]

26 Statistisches Amt Saarland. Daten der natürlichen Bevölkerungsbewegung. Totgeburten Saarland 2017 2020. Saarbrücken: Statistisches Amt Saarland 2020 [cited 3.11.2020] [Data request]

27 Statistisches Landesamt Baden-Württemberg. Totgeburten nach Monaten der Jahre 2000 bis 2020 (vorläufige Zahlen). Stuttgart: Statistisches Landesamt Baden-Württemberg 2020 [cited 21.10.2020] [Data request]

28 Statistisches Landesamt Bremen. Totgeburten nach Monaten im Land Bremen. Bremen: Statistisches Landesamt Bremen 2020 [cited 9.12.2020] [Data request]

29 Statistisches Landesamt des Freistaates Sachsen. Totgeborene des Freistaates Sachsen 2017 bis Juli 2020 nach Berichtsmonaten. Kamenz: Statistisches Landesamt des Freistaates Sachsen 2020 [cited 27.10.2020] [Data request]

30 Statistisches Amt für Hamburg und Schleswig-Holstein. Anzahl der Totgeburten in Schleswig-Holstein nach Geburtsmonat in den Jahren 2017 bis 2020 . Hamburg: Statistisches Amt für Hamburg und Schleswig-Holstein 2020 [cited 30.10.2020] [Data request]

31 Statistisches Landesamt Rheinland-Pfalz. Totgeborene in Rheinland-Pfalz nach Monaten 2017 - 2020. Bad Ems: Statistisches Landesamt Rheinland-Pfalz 2020 [cited 29.10.2020] [Data request] 
32 Statistisches Landesamt Sachsen-Anhalt. Totgeborene in Sachsen-Anhalt 2017 - 2020. Halle (Saale): Statistisches Landesamt Sachsen-Anhalt 2020 [cited 27.10.2020] [Data request]

33 Thüringer Landesamt für Statistik. Totgeborene in Thüringen in den Jahren 1991 bis 2002 nach Monaten. Erfurt: Thüringer Landesamt für Statistik 2020 [cited 24.11.2020] [Data request]

34 Thüringer Landesamt für Statistik. Natürliche Bevölkerungsbewegung in Thüringen 2019. Erfurt: Thüringer Landesamt für Statistik 2020 [cited 18.11.2020] Available from: https://statistik.thueringen.de/webshop/webshop.asp?ansicht=frersch\&ve=01201

35 Thüringer Landesamt für Statistik. Natürliche Bevölkerungsbewegung in Thüringen 2018. Erfurt: Thüringer Landesamt für Statistik 2019 https://statistik.thueringen.de/webshop/webshop.asp?ansicht=frersch\&ve=01201 [Accessed on 18.11.2020]

36 Thüringer Landesamt für Statistik: Natürliche Bevölkerungsbewegung in Thüringen 2017. Erfurt: Thüringer Landesamt für Statistik 2018 [cited 18.11.2020] Available from: https://statistik.thueringen.de/webshop/webshop.asp?ansicht=frersch\&ve=01201 [Accessed on 18.11.2020]

37 Thüringer Landesamt für Statistik: Natürliche Bevölkerungsbewegung in Thüringen 2016. Erfurt: Thüringer Landesamt für Statistik 2017 [cited 18.11.2020] Available from https://statistik.thueringen.de/webshop/webshop.asp?ansicht=frersch\&ve=01201 [Accessed on 18.11.2020]

38 Thüringer Landesamt für Statistik : Natürliche Bevölkerungsbewegung in Thüringen 2015. Erfurt: Thüringer Landesamt für Statistik 2016 [cited 18.11.2020] Available from: https://statistik.thueringen.de/webshop/webshop.asp?ansicht=frersch\&ve=01201

39 Thüringer Landesamt für Statistik: Natürliche Bevölkerungsbewegung in Thüringen 2014. Erfurt: Thüringer Landesamt für Statistik 2015 [cited 18.11.2020] Available from: https://statistik.thueringen.de/webshop/webshop.asp?ansicht=frersch\&ve=01201

40 Thüringer Landesamt für Statistik: Natürliche Bevölkerungsbewegung in Thüringen 2013. Erfurt: Thüringer Landesamt für Statistik 2014 [cited 18.11.2020] Available from: https://statistik.thueringen.de/webshop/webshop.asp?ansicht=frersch\&ve=01201

41 Thüringer Landesamt für Statistik: Natürliche Bevölkerungsbewegung in Thüringen 2012. Erfurt: Thüringer Landesamt für Statistik 2013 [cited 18.11.2020] Available from: https://statistik.thueringen.de/webshop/webshop.asp?ansicht=frersch\&ve=01201

42 Thüringer Landesamt für Statistik: Natürliche Bevölkerungsbewegung in Thüringen 2011. Erfurt: Thüringer Landesamt für Statistik 2012 [cited 18.11.2020] Available from: https://statistik.thueringen.de/webshop/webshop.asp?ansicht=frersch\&ve=01201

43 Thüringer Landesamt für Statistik: Natürliche Bevölkerungsbewegung in Thüringen 2010. Erfurt: Thüringer Landesamt für Statistik 2011 [cited 18.11.2020] Available from: https://statistik.thueringen.de/webshop/webshop.asp?ansicht=frersch\&ve=01201

44 Thüringer Landesamt für Statistik: Natürliche Bevölkerungsbewegung in Thüringen 2009. Erfurt: Thüringer Landesamt für Statistik 2010 [cited 18.11.2020] Available from: https://statistik.thueringen.de/webshop/webshop.asp?ansicht=frersch\&ve=01201

45 Thüringer Landesamt für Statistik: Natürliche Bevölkerungsbewegung in Thüringen 2008. Erfurt: Thüringer Landesamt für Statistik 2009 [cited 18.11.2020] Available from: https://statistik.thueringen.de/webshop/webshop.asp?ansicht=frersch\&ve=01201 
46 Thüringer Landesamt für Statistik: Natürliche Bevölkerungsbewegung in Thüringen 2007. Erfurt: Thüringer Landesamt für Statistik 2008 [cited 18.11.2020] Available from: https://statistik.thueringen.de/webshop/webshop.asp?ansicht=frersch\&ve=01201

47 Thüringer Landesamt für Statistik: Natürliche Bevölkerungsbewegung in Thüringen 2006. Erfurt: Thüringer Landesamt für Statistik 2007 [cited 18.11.2020] Available from: https://statistik.thueringen.de/webshop/webshop.asp?ansicht=frersch\&ve=01201

48 Thüringer Landesamt für Statistik: Natürliche Bevölkerungsbewegung in Thüringen 2005. Erfurt: Thüringer Landesamt für Statistik 2006 [cited 18.11.2020] Available from: https://statistik.thueringen.de/webshop/webshop.asp?ansicht=frersch\&ve=01201

49 Thüringer Landesamt für Statistik: Natürliche Bevölkerungsbewegung in Thüringen 2004. Erfurt: Thüringer Landesamt für Statistik 2005 [cited 18.11.2020] Available from: https://statistik.thueringen.de/webshop/webshop.asp?ansicht=frersch\&ve=01201

50 Thüringer Landesamt für Statistik: Natürliche Bevölkerungsbewegung in Thüringen 2003. Erfurt: Thüringer Landesamt für Statistik 2004 [cited 18.11.2020] Available from: https://statistik.thueringen.de/webshop/webshop.asp?ansicht=frersch\&ve=

51 Hastie T J, Tibshirani R J. Generalized Additive Models. Chapman \& Hall 1990, London, UK.

52 Wood S. Generalized Additive Models: An Introduction with R. Chapman \& Hall 2006.

53 Cameron A C, Trivedi P K. Regression Analysis of Count Data. Second Edition. Cambridge University Press 2012, Cambridge, UK.

$54 \quad$ Lawless J F. Negative binomial and mixed Poisson regression. The Canadian Journal of Statistics 1987, 15:209-225.

55 Eilers P H C, Marx B D. Flexible Smoothing with B-splines and Penalties. Statistical Science 1996, 11(2):89-102.

56 Camarda C G. MortalitySmooth: An R package for smoothing Poisson counts with P-splines. Journal of Statistical Software 2012, 50(1):1-24.

$57 \quad$ Currie I D, Durban M, Eilers P H C. Smoothing and forecasting mortality rates. Statistical Modelling 2004, 4:279-298.

58 Schwarz C, Schäfers R, Loytved C, et al. Temporal trends in fetal mortality at and beyond term and induction of labor in Germany 2005-2012: data from German routine perinatal monitoring. Arch Gynecol Obstet 2016, 293(2), 335-343.

59 Bay B, Boie S, Kesmodel U S. Risk of stillbirth in low-risk singleton term pregnancies following fertility treatment: a national cohort study. BJOG: An International Journal of Obstetrics \& Gynaecology 2019, 126(2), 253260.

60 Khalil A, Kalafat E, Benlioglu C, et al. SARS-CoV-2 infection in pregnancy: A systematic review and meta-analysis of clinical features and pregnancy outcomes. EClinicalMedicine 2020, 25, 100446. 
61 Deutsche Interdisziplinäre Vereinigung für Intensiv- und Notfallmedizin (DIVI) e.V. Anzahl gemeldeter intensivmedizinisch behandelter COVID-19-Fälle. Deutschland. 2021. [cited 12.04. 2021] Available from: https://www.intensivregister.de/ - /aktuelle-lage/zeitreihen

62 Statistisches Bundesamt (Destatis). Statistik der Geburten. Qualitätsbericht zur Statistik der Geburten. 2014 - 2015. 2017. [cited 12.04. 2021] Available from:

https://www.destatis.de/DE/Methoden/Qualitaet/Qualitaetsberichte/Bevoelkerung/geburten.pdf?__blob=publication File

63 German Board and College of Gynecology and Obstetrics: COVID-19: Keine Angst vor

Krankenhausbehandlungen oder Klinikgeburten. Pressemitteilung der Deutschen Gesellschaft für Gynäkologie und Geburtshilfe e.V. (DGGG). German Board and College of Gynecology and Obstetrics. 2020 [cited 26.01.2021] Available from:

https://www.dggg.de/fileadmin/documents/Weitere_Nachrichten/2020/20200422_GBCOG_COVID-19_KeineAngst-vor-Klinikgeburten.pdf 